\title{
CloudSat and A-Train Observations of Tropical Cyclones
}

\author{
Stephen L. Durden ${ }^{*}$, Simone Tanelli and Gregg Dobrowalski
}

Jet Propulsion Laboratory, California Institute of Technology, 4800 Oak Grove Dr., Pasadena, CA 91109, USA

\begin{abstract}
The CloudSat 94-GHz Cloud Profiling Radar was designed to provide global information on the vertical structure of clouds. It was launched in April 2006, joining the A-Train of earth science satellites. Although primarily focused on clouds and climate, the CloudSat radar also provides a unique view of the vertical structure of clouds in tropical cyclones. The authors use data from CloudSat and other A-Train satellite constellation missions to examine tropical cyclone cloud properties. They consider several case studies and then examine cloud statistics based on seventeen tropical cyclone overpasses. In addition to the new qualitative view of cloud structure provided by CloudSat, the CloudSat and other ATrain products also contain quantitative estimates of cloud properties. Although the accuracy of these products in tropical cyclones is not validated by direct comparison, the authors do find reasonable agreement with previous in situ measurements.
\end{abstract}

\section{INTRODUCTION}

The CloudSat Cloud Profiling Radar (CPR) is the first spaceborne cloud radar, operating at $\mathrm{W}$-band $(94 \mathrm{GHz})$ and providing a measurement of radar reflectivity versus altitude in a nadir slice along the satellite track. CloudSat flies with Aqua, CALIPSO, and other missions in the afternoon satellite constellation referred to as the A-Train [1]. The A-Train provides active and passive atmospheric measurements at microwave, infrared, and optical wavelengths. While passes of the nadir-pointing CPR antenna beam over tropical cyclone cores are infrequent, they do happen on occasion and provide unique data on tropical cyclone structure [2].

Lower frequency radars (e.g., Ku-band and below) have a long history of use in tropical cyclone investigations [3]. Observations by aircraft and ground-based radars have provided detailed observations of the 3-D reflectivity distribution of liquid and ice hydrometeors. These radars, however, cannot sense smaller particles (e.g., clouds) due to their relatively low frequency, and much of our current knowledge of the distribution of cloud particles has been derived from in situ aircraft observations. The 3-mm wavelength used by CPR severely attenuates in precipitation but excels in observing cloud structure. It is, therefore, complementary to lower frequency radar and provides a new approach to investigating tropical cyclone cloud structure. We begin by discussing the cases used here and the various instruments used as data sources. We then examine several cases in detail and attempt to combine results from these and other cases to gain a statistical picture of the microphysical properties observed by CloudSat and other A-Train instruments. A discussion section compares the observations here with previous observations and theory.

\footnotetext{
*Address correspondence to this author at the Jet Propulsion Laboratory, 4800 Oak Grove Dr., Pasadena, CA 91109, USA; Tel: 818-354-4719; Fax: 818-393-6440; E-mail: sdurden@jpl.nasa.gov
}

\section{DATA AND METHODOLOGY}

The data used in this study were based on passes of the CPR over tropical cyclones. We identified seventeen cases in which the CPR nadir-pointing beam passed close to the center of a category one (Saffir-Simpson scale) or higher tropical cyclone. The passes are listed in Table 1. The minimum distance is the distance between the storm center and the CPR beam's closest approach. Also listed in Table $\mathbf{1}$ are storm intensity metrics at time of overpass, minimum sea level pressure (MSLP), maximum wind speed, and SaffirSimpson (SS) category, based on information from the $\mathrm{Na}$ tional Hurricane Center, the Joint Typhoon Warning Center, and the Unisys archive (weather.unisys.com/hurricane). For each CloudSat overpass we created a merged file containing the CPR reflectivity and Level 2 products derived from CPR. We also included particle phase information derived from the depolarized channel of the lidar on the NASA/CNES CALIPSO mission and information from the passive microwave radiometer on Aqua. A list of the data products used is provided in Table 2 . It should be noted that the accuracy of the various products is, in many cases, still being evaluated. The statistics of ice retrievals from CloudSat are compared with previous in situ measurements later in the paper.

\section{CASE STUDY: HURRICANE ILEANA}

Hurricane Ileana formed in the Eastern Pacific on 21 August 2006 as a tropical depression. It moved westnorthwest and intensified, reaching hurricane strength on 22 August. The CloudSat/A-Train overpass occurred when it was centered near $19 \mathrm{~N}$ and $113 \mathrm{~W}$ on 23 August at 21Z, soon after reaching a maximum estimated intensity of 955 $\mathrm{hPa}$ and $55 \mathrm{~m} / \mathrm{s}$. Weakening had probably already begun; by $06 \mathrm{Z}$ on the $24^{\text {th }}$, its intensity was estimated at $960 \mathrm{hPa}$ and 45 $\mathrm{m} / \mathrm{s}$. Fig. (1) shows visible satellite data, along with the CloudSat track; the track passed into the eye but not through the center of the eye; hence, the CPR-observed eye is smaller than the actual eye. This same overpass was used 
Table 1. CloudSat Tropical Cyclone Overpasses Used in this Study

\begin{tabular}{|c|c|c|c|c|c|c|c|c|}
\hline Name & CloudSat Granule & Basin & Date & UTC & MSLP (hPa) & Wind $(\mathbf{m} / \mathbf{s})$ & SS Cat & Min Dist (km) \\
\hline Ewiniar & 973 & W Pac & 4 Jul 2006 & 0444 & 944 & 52 & 3 & 20 \\
\hline Daniel & 1253 & E Pac & $23 \mathrm{Jul} 2006$ & 1053 & 948 & 57 & 3 & 20 \\
\hline Prapiroon & 1396 & W Pac & 2 Aug 2006 & 0553 & 976 & 34 & 1 & 0 \\
\hline Ileana & 1711 & E Pac & 23 Aug 2006 & 2102 & 955 & 55 & 3 & 0 \\
\hline Ioke & 1853 & $\mathrm{C} \mathrm{Pac}$ & 2 Sep 2006 & 0103 & 940 & 60 & 3 & 40 \\
\hline Gordon & 2058 & Atl & 16 Sep 2006 & 1700 & 987 & 33 & 1 & 0 \\
\hline Helene & 2065 & Atl & 17 Sep 2006 & 0506 & 984 & 33 & 1 & 0 \\
\hline Yagi & 2130 & W Pac & $21 \mathrm{Sep} 2006$ & 1612 & 920 & 70 & 5 & 100 \\
\hline Durian & 3202 & W Pac & 4 Dec 2006 & 0615 & 980 & 33 & 1 & 0 \\
\hline Utor & 3296 & W Pac & 10 Dec 2006 & 1754 & 965 & 45 & 2 & 20 \\
\hline Jaya & 4945 & S Ind & 2 April 2007 & 2203 & 950 & 48 & 2 & 100 \\
\hline Dean & 6937 & Atl & 17 Aug 2007 & 1750 & 961 & 55 & 3 & 10 \\
\hline Fame & 9292 & S Ind & 26 Jan 2008 & 1053 & 975 & 34 & 1 & 0 \\
\hline Jokwe & 9882 & S Ind & 6 Mar 2008 & 1116 & 967 & 38 & 1 & 30 \\
\hline Jokwe & 9933 & S Ind & 10 Mar 2008 & 2231 & 960 & 40 & 2 & 0 \\
\hline Ike & 12536 & Atl & 5 Sep 2008 & 0605 & 945 & 58 & 3 & 25 \\
\hline Jangmi & 12834 & W Pac & 25 Sep 2008 & 1712 & 960 & 40 & 1 & 0 \\
\hline
\end{tabular}

Minimum distance to center has been set to zero in cases with data collected in the eye.

Table 2. CloudSat and Other A-Train Products Used in this Study

\begin{tabular}{l}
\hline CloudSat Level 2B GEOPROF - cloud mask and radar reflectivity \\
\hline CloudSat Level 2B CLDCLASS - cloud classification \\
\hline $\begin{array}{l}\text { CloudSat Level 2B TAU - cloud optical depth, derived from } \\
\text { Aqua/MODIS }\end{array}$ \\
\hline CloudSat Level 2B CWC-RO - radar-only liquid and ice water content \\
\hline $\begin{array}{l}\text { CloudSat Level 2B GEOPROF-Lidar - combined CloudSat and CA- } \\
\text { LIPSO cloud mask }\end{array}$ \\
\hline AMSR-E L2A Resampled Brightness Temperatures \\
\hline AMSR-E L2B Global Swath Rain Rate/Type GSFC Profiling Algorithm \\
\hline $\begin{array}{l}\text { AMSR-E L2B Global Swath Ocean Products derived from Wentz Algo- } \\
\text { rithm }\end{array}$ \\
\hline CALIPSO L2 Lidar Vertical Feature Mask \\
\hline
\end{tabular}

by Luo et al. [4] in their work on intensity estimation. Fig. (2, upper) shows the corresponding reflectivity data; the eye is the second gap in the reflectivity (from the left), near along-track distance $460 \mathrm{~km}$. The first gap, near distance 370 $\mathrm{km}$, is a relatively clear area between the eyewall and a rainband. While moats may surround the eyewall in some storms [5], this feature did not fully circle the storm, since it is not visible on the other side of the eye. Inspection of SSMI 85$\mathrm{GHz}$ data showed that it extended slightly more than halfway around the storm. Fig. (2, lower) shows the cloud classification product for Ileana; Table $\mathbf{3}$ provides the relationship between the classification symbols and the cloud type [6].

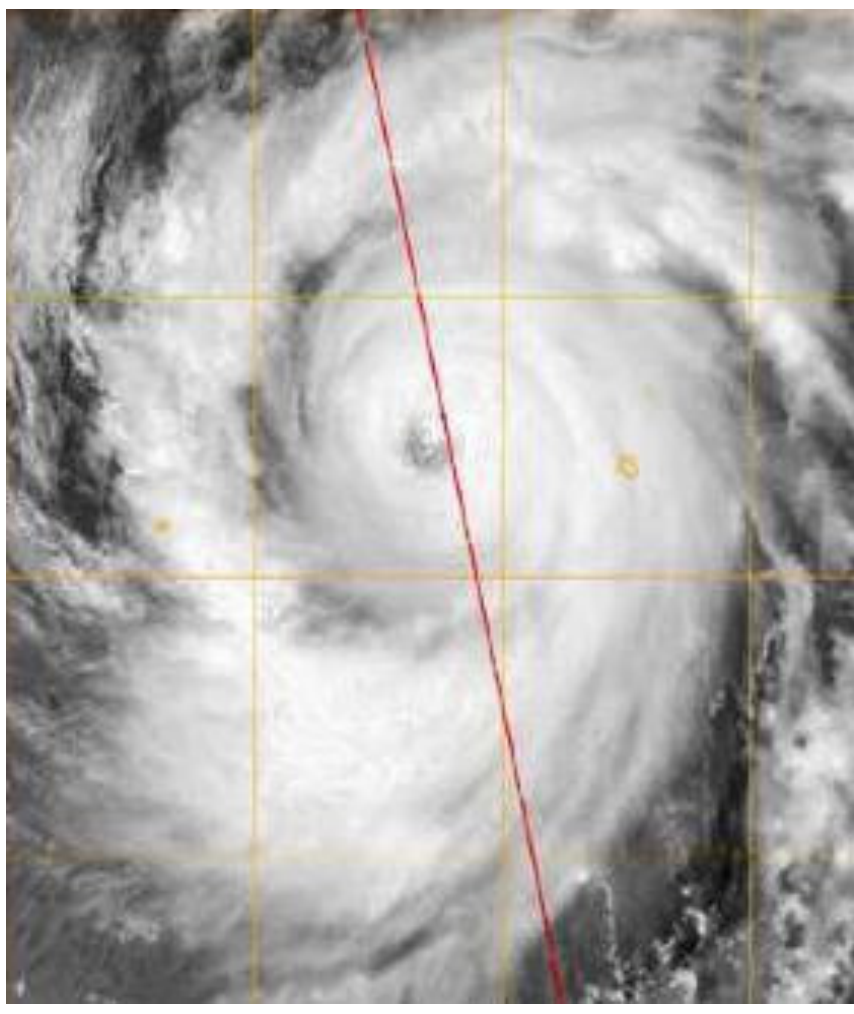

Fig. (1). Hurricane Ileana in the eastern Pacific Ocean in visible satellite imagery on 23 August 2006 at 21Z. Red line across image is Cloudsat track, starting from the bottom of the image and ending at the top of the image. Image courtesy Naval Research Laboratory, Monterey. 

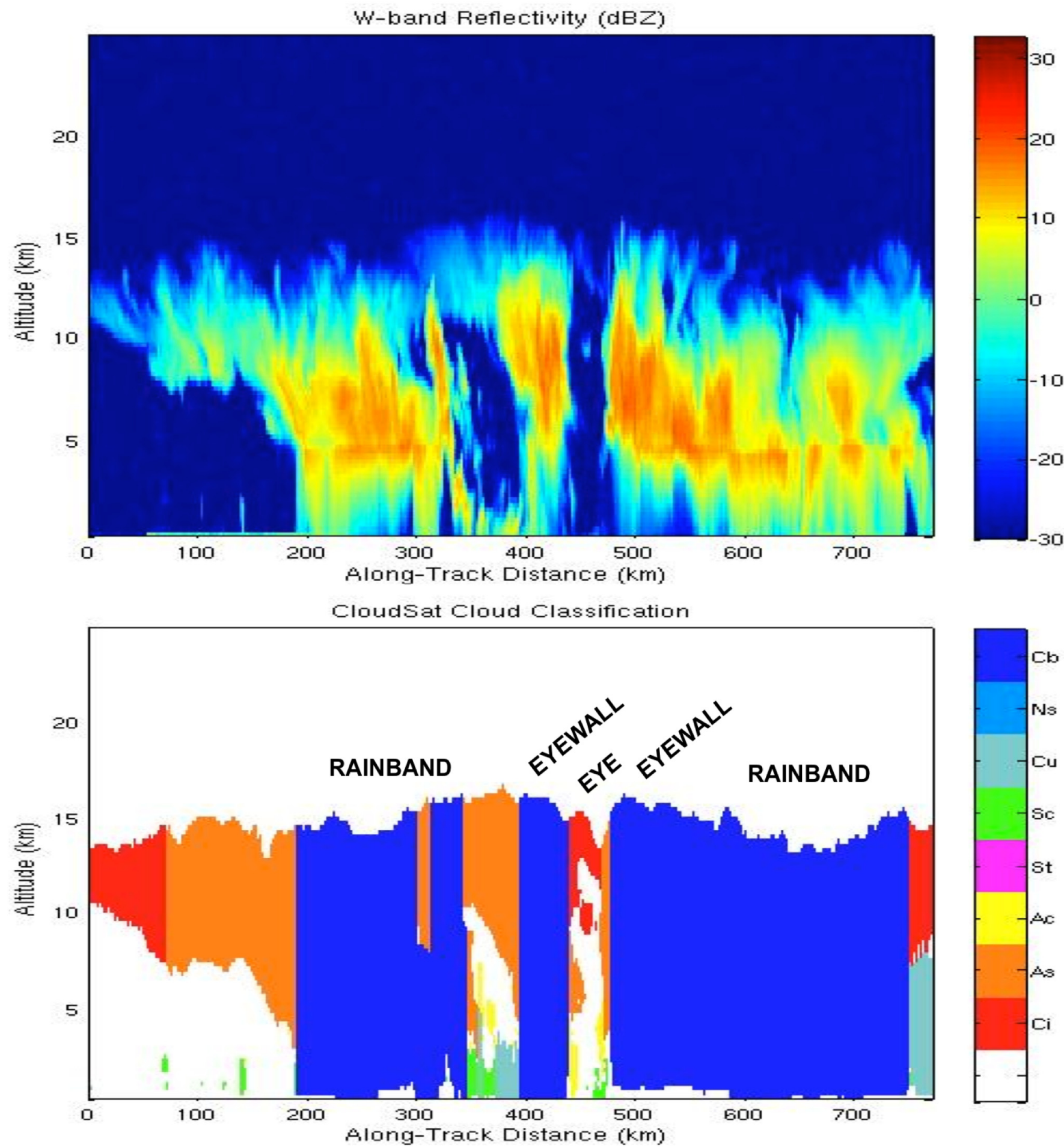

Fig. (2). Upper image is CloudSat CPR vertical reflectivity slice through Hurricane Ileana, along the red line in Fig. (1). The image starts at left, corresponding to the bottom of the image in Fig. (1). The first gap in the reflectivity is a clear region between a rainband and the eyewall. The second gap, near along-track distance $460 \mathrm{~km}$, is the eye. Lower image is the Level 2B cloud class product; see Table 3 for meaning of the classes.

The cirrus canopy, one of the more obvious features in visible images of tropical cyclones [7], is identified in the radar data, although a large portion of the canopy is classified as altostratus. The classification methodology is likely more suitable for mid-latitudes, and the canopy should be considered thick cirrus. A thin layer of cirrus extends over the eye, and low clouds (stratocumulus) can be seen in the eye. Stratocumulus, altocumulus, and cumulus clouds are especially evident in the gap or possible moat to the left of the eye. The eyewall and rainbands are identified as deep convection, although the clear signature of a melting layer of precipitation in the reflectivity data (i.e., the horizontal feature at 
about $4.5 \mathrm{~km}$ altitude) indicates that these regions would probably be better characterized as stratiform precipitation.

Table 3. CloudSat Cloud Classification

\begin{tabular}{|c|c|}
\hline Symbol & Classification \\
\hline \hline $\mathrm{Ci}$ & cirrus \\
\hline $\mathrm{As}$ & altostratus \\
\hline $\mathrm{Ac}$ & altocumulus \\
\hline $\mathrm{St}$ & stratus \\
\hline $\mathrm{Sc}$ & stratocumulus \\
\hline $\mathrm{Cu}$ & cumulus \\
\hline $\mathrm{Ns}$ & nimbostratus \\
\hline $\mathrm{Cb}$ & deep convection (cumulonimbus) \\
\hline
\end{tabular}

Fig. (3, upper left) shows the AMSR-E polarization corrected temperature (PCT) [8]. Lowest regions correspond to the eyewall where convectively generated ice particles scatter $89 \mathrm{GHz}$ radiation and cause a reduction of the brightness temperature. The temperatures shown here are rather high but agree well with an SSMI pass a few hours later. The lack of strong ice scattering is in agreement with the identifica-
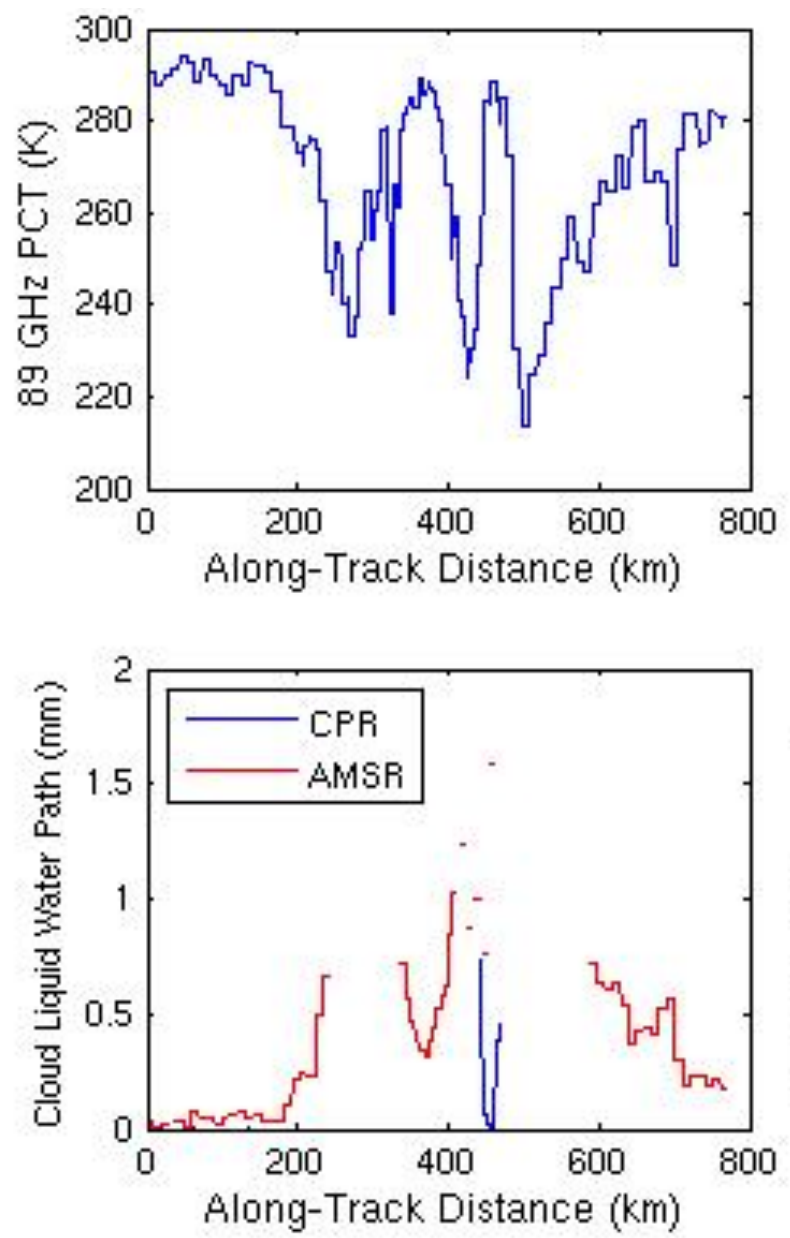

tion of Ileana as a weakening storm. The upper right plot in Fig. (3) provides various measures of the shape of the upper boundary of the storm. The lidar-measured boundary is the highest in altitude, since the lidar is sensitive to the smallest particles and attenuates rapidly. The three lines below it show various radar reflectivity contours. Larger reflectivity values correspond to lower contour altitude and greater altitude variability. The $+15 \mathrm{dBZ}$ radar contour is a good indicator of the altitude reached by larger ice particles and is negatively correlated with the $89-\mathrm{GHz}$ PCT. Fig. (3, lower left) shows the cloud liquid water path from AMSR-E and from CloudSat. There is little overlap in areas with good retrievals. The data appear complementary, with the radar retrievals failing in attenuating precipitation, exactly the situation in which the lower frequency radiometer channels have enough signal for retrievals. The lower right plot is the rain rate at the surface from AMSR-E; it exceeds $20 \mathrm{~mm} / \mathrm{h}$ in the eyewall region. Also shown is the fraction of rain that is convective, again based on AMSR-E.

The CloudSat L2B Cloud Water Content product produces estimates of ice quantities; these are displayed as images in Fig. (4). The retrieval assumes a lognormal particle size distribution (PSD) [9]. The PSD width parameter is shown in the lower right image; the distribution narrows with increasing altitude. The other images indicate that ice water content, particle concentration, and radius tend to peak
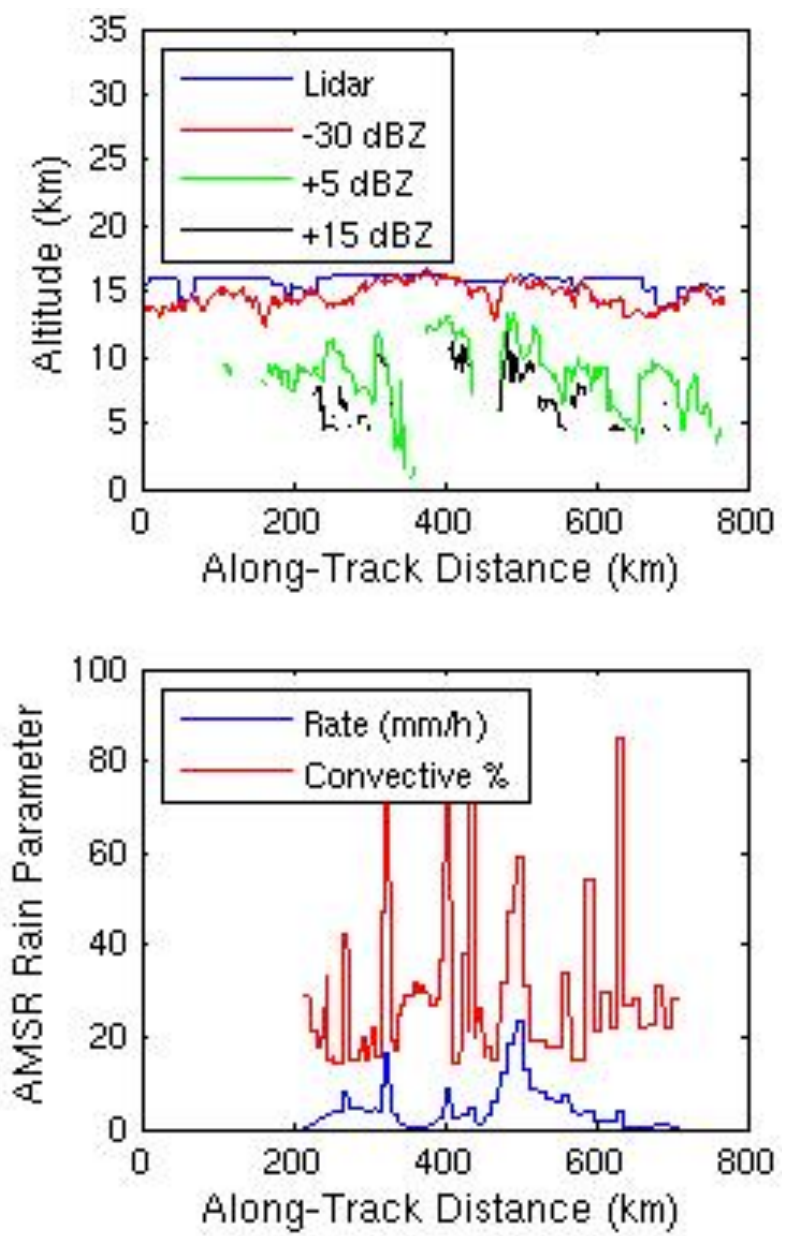

Fig. (3). Plots of various parameters from AMSR, CPR, and CALIPSO lidar from Ileana versus along-track distance. Eye is centered near $460 \mathrm{~km}$. 

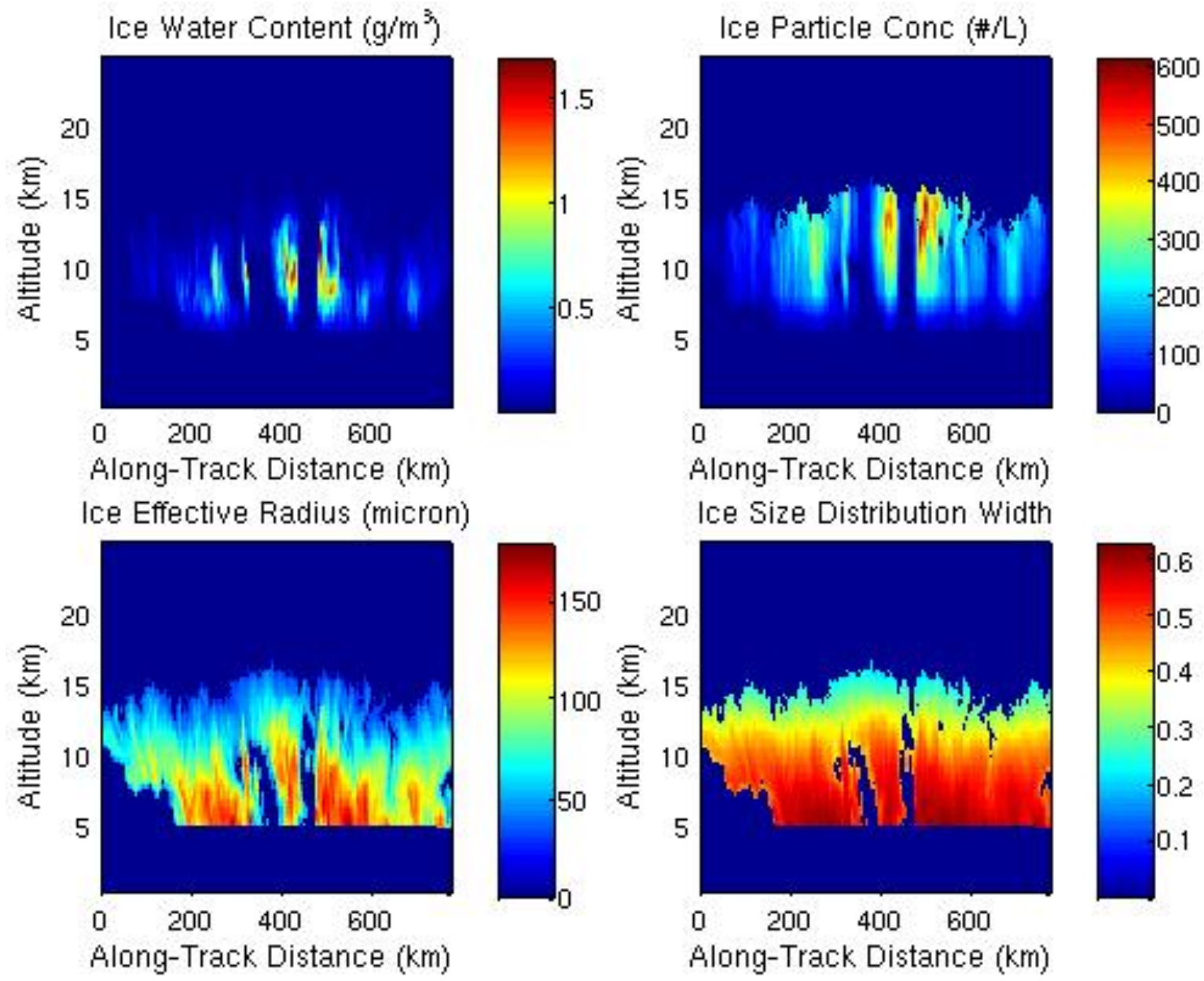

Fig. (4). Images of CloudSat Cloud Water products for Hurricane Ileana. Along-track and vertical indices correspond to Fig. (2). Eye is near along-track distance $450 \mathrm{~km}$.

in the eyewall. The mean particle radius and ice water content decrease with increasing altitude, while particle concentration increases with altitude. An independent estimate of column-integrated mean effective radius is derived from the Aqua MODIS and provided in the CloudSat 2B Tau product. It peaks at roughly $25 \mu \mathrm{m}$ over the inner core of the storm, smaller than the values of particle radius near the very top of the cirrus layer in Fig (4, lower left).

\section{CASE STUDY: TYPHOON PRAPIROON}

CPR also passed directly through the eye of Typhoon Prapiroon in 2006. Prapiroon became a tropical depression on 31 July and reached typhoon status on 2 August at 06Z . Its maximum wind speed briefly reached $35 \mathrm{~m} / \mathrm{s}$ at $00 \mathrm{Z}$ on the $3^{\text {rd }}$ before weakening. The CloudSat overpass occurred just as it reached typhoon strength, near $19 \mathrm{~N}$ and $114 \mathrm{E}$. Fig. (5) shows visible satellite data, along with the CloudSat track; the track passed very close to the center of the eye. Fig. (6, upper) shows the corresponding reflectivity data; the eye is the second gap in the reflectivity (from the left), near along-track distance $400 \mathrm{~km}$. The eye is approximately 60 $\mathrm{km}$ in diameter at the surface; the eyewall slopes outward, increasing the eye diameter to nearly $100 \mathrm{~km}$ at $13 \mathrm{~km}$ altitude. The eyewall slope is larger toward the left side of the eye, which is toward the south. At the time of the overpass the storm motion was toward the northwest.

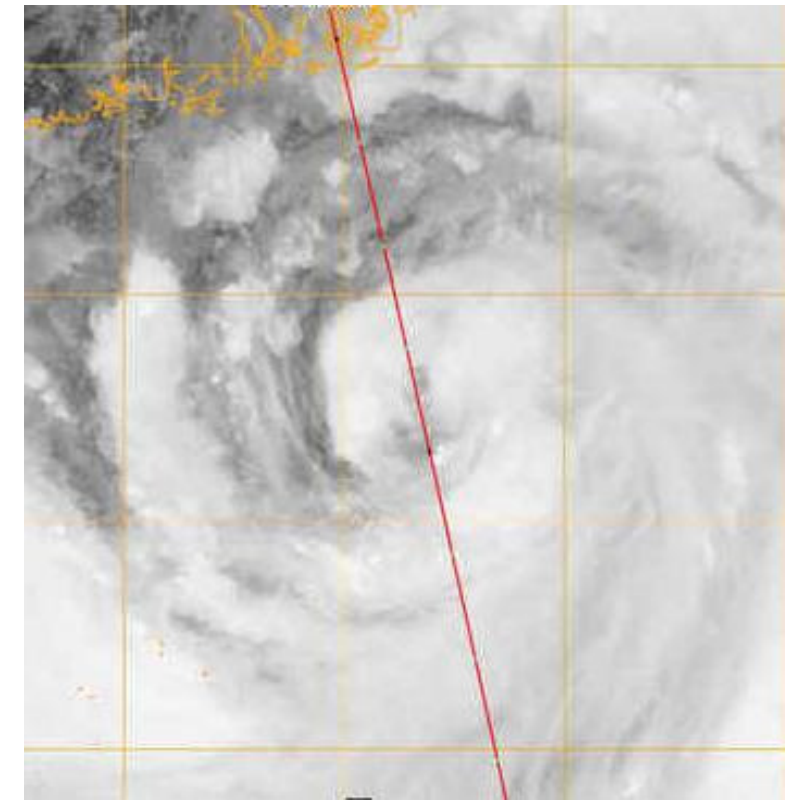

Fig. (5). Typhoon Prapiroon in the western Pacific Ocean in visible satellite imagery on 2 August 2006 at 06Z UTC. Red line across image is Cloudsat track, starting from the bottom of the image and ending at the top of the image. Image courtesy Naval Research Laboratory, Monterey. 

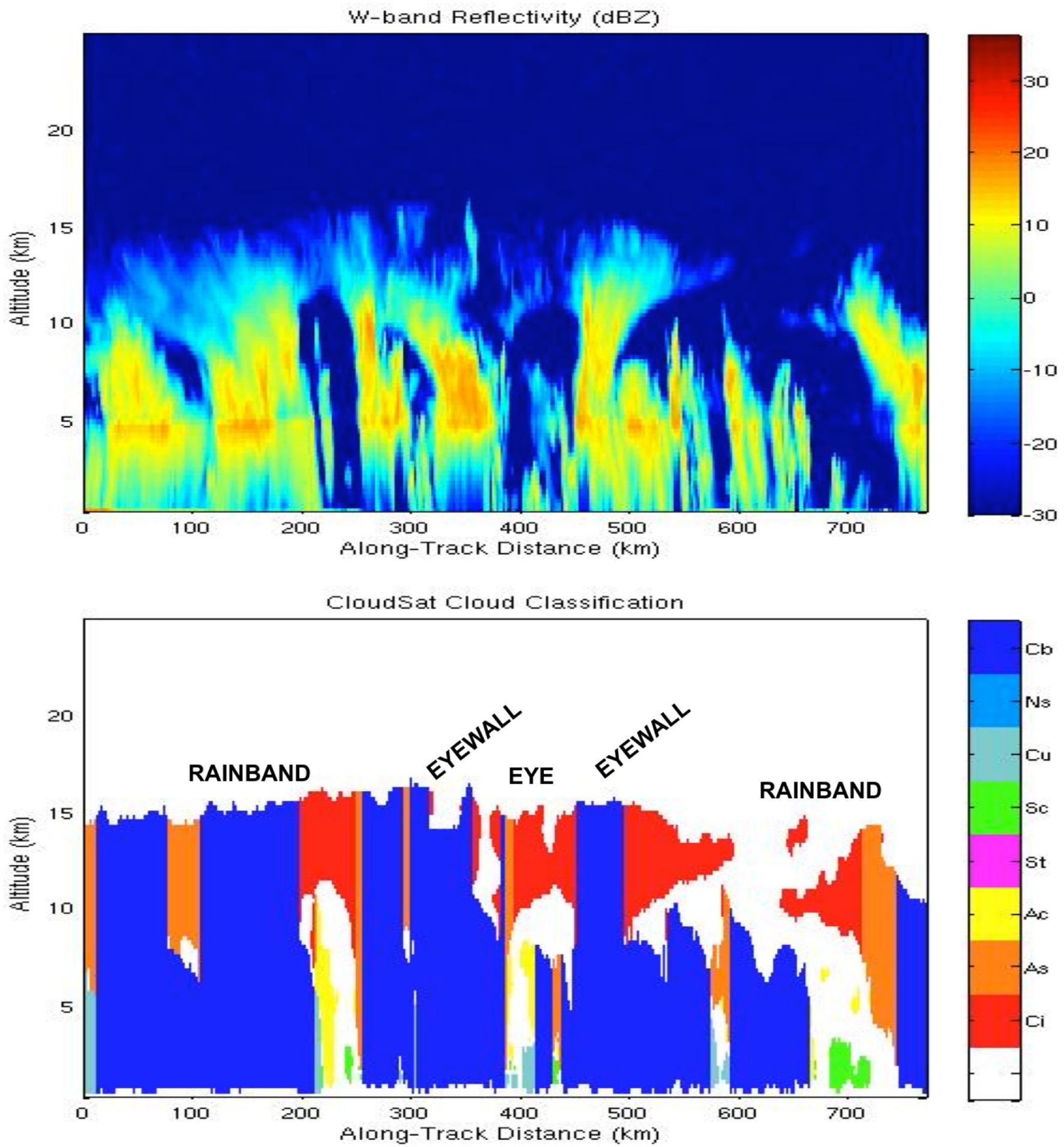

Fig. (6). Upper image is CloudSat CPR vertical reflectivity slice through Typhoon Prapiroon, along the red line in Fig. (1). The image starts at left, corresponding to the bottom of the image in Fig. (1). The first gap in the reflectivity is a clear region between a rainband and the eyewall. The second gap, near distance $400 \mathrm{~km}$, is the eye. Lower image is the Level 2B cloud class product.

Fig. (6, lower) shows the cloud classification product for Prapiroon. The cirrus canopy is identified in the radar data, and a layer of thin cirrus extends over the eye. The overpass went nearly through the center of Prapiroon, and CPR observed low clouds in the center of the eye. These clouds are classified as altostratus, altocumulus, stratocumulus, and cumulus. The reflectivity near the center of the eye (the "hub" cloud at along-track distance $410 \mathrm{~km}$ ) is large enough
$(10 \mathrm{dBZ})$ that there may also be some precipitation; the area just to the right is classified as deep convection. The CALIPSO lidar vertical feature mask product (not shown) identifies almost all of the cloud seen by the lidar as ice; this corresponds to the thick cirrus canopy, not penetrated by the lidar signal. An exception is in the eye where some of the mid-level cloud is identified as liquid. 

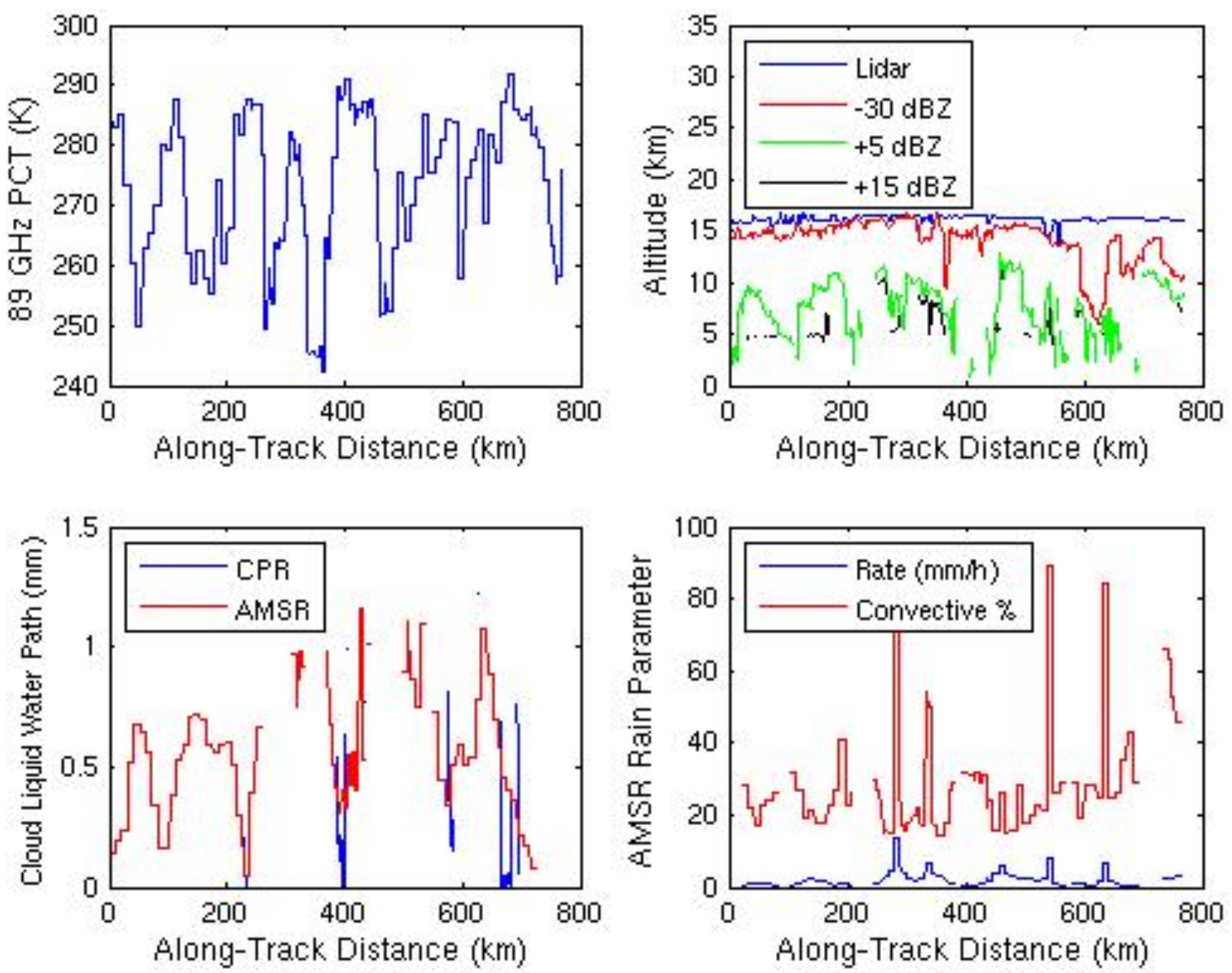

Fig. (7). Plots of various parameters from AMSR, CPR, and CALIPSO lidar from Prapiroon versus along-track distance. Eye is centered near $400 \mathrm{~km}$.

Fig. (7) provides the AMSR-E PCT, cloud upper boundaries, cloud liquid water, and surface rain rate, as provided for Ileana in Fig. (3). Cloud ice retrieval results are displayed as images in Fig. (8). The ice water content in Prapiroon's eyewall is less distinct than that of Ileana, as is also the case for the particle concentration. The effective radius (lower left) shows more horizontal variability than seen in Ileana. The PSD (lower right) width has similar behavior to that of Fig. (4). The particle mean effective radius from the $2 \mathrm{~B}$ Tau product is near $25 \mu \mathrm{m}$, roughly the same as measured for Ileana and, again, somewhat smaller than the particle size measured by CPR at the very top of the cirrus layer.

\section{ADDITIONAL CASES: GORDON, HELENE, DURIAN, JANGMI}

The four additional cases in Figs. $(\mathbf{9}, \mathbf{1 0})$ were direct eye overpasses over storms sufficiently well-organized to have a distinct eye. At the time of the overpass, Hurricane Gordon had weakened from a major hurricane; it had only a southern eyewall, the sloping feature seen in the left side of the reflectivity image near along-track distance $100 \mathrm{~km}$. To the right is the eye itself, starting around along-track distance $125 \mathrm{~km}$, followed by some convection where the northern eyewall had been. The clouds in the eye are classified as stratocumulus by the Level 2B classification product. In contrast to Gordon, Hurricane Helene was intensifying when observed by CloudSat. The pass went very close to the center of the eye. The eyewall deep convection at left transitions to cumulus near along-track distance $60 \mathrm{~km}$; the near surface clouds in the eye are classified as stratocumulus. There are also some bins classified as altocumulus at mid-levels near the center of the eye.

At the time of the overpass, Typhoon Durian was weakening, having had supertyphoon status several days earlier on 29 November. The eyewall at left (around along track distance 110) does not appear very strong but is still classified as deep convection. Toward the right, the eyewall transitions to cumulus clouds (near along-track distance $125 \mathrm{~km}$ ) and then to nimbostratus (around distance $140 \mathrm{~km}$ ). The nimbostratus continues through the eye to along-track distance $200 \mathrm{~km}$. A small amount of altocumulus occurs at the transition to the right eyewall (classified as deep convection). Overall the second eyewall appears even weaker than the left eyewall; both are consistent with a weakening storm. As noted previously, the CloudSat cloud classification should be viewed with some skepticism since it was de- 

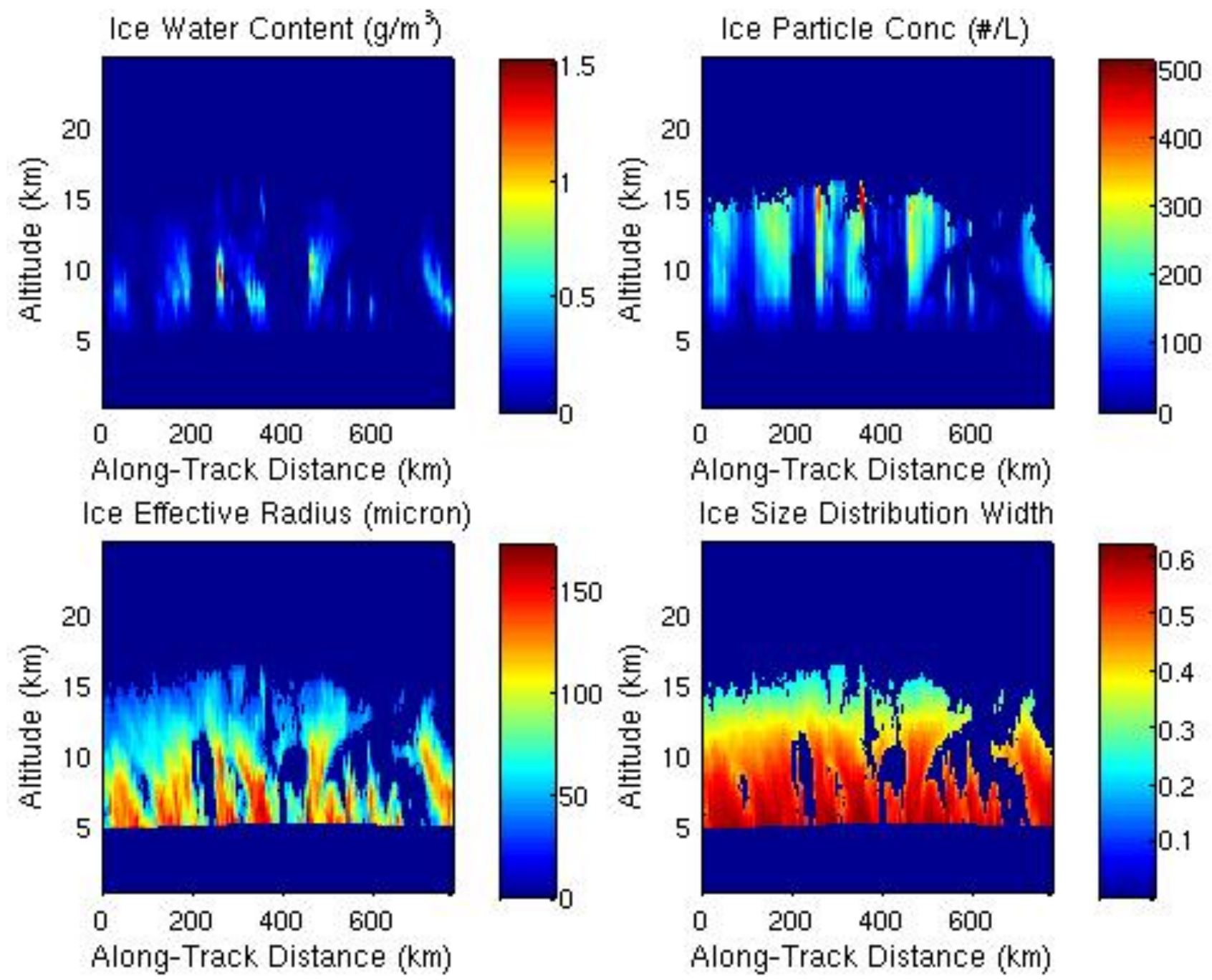

Fig. (8). Images of CloudSat Cloud Water products for Typhoon Prapiroon. Eye is near along-track distance $400 \mathrm{~km}$.

signed for global cloud studies rather than clouds in tropical cyclone eyes. In the case of Durian, visual inspection of the CPR data suggests that the two regions classified as cumulus and altocumulus are actually the higher edge of a region of moderate to intense precipitation likely associated with eyewall convection. The portion classified as nimbostratus is probably hub clouds and associated drizzle.

Typhoon Jangmi was strengthening and reached supertyphoon status two days after the CPR eye observation. The eye is covered with a cloud layer, a cirrus shield misclassified as altostratus; it extends from 9 to $16 \mathrm{~km}$ in altitude and so is an ice cloud. There is a layer of clouds in the eye just above the surface from along-track distance $130 \mathrm{~km}$ to 170 $\mathrm{km}$ that is classified as mostly stratocumulus. At the right side of the eye near along-track distance $160 \mathrm{~km}$ the stratocumulus layer is interrupted by altocumulus extending upward to altitude $4.5 \mathrm{~km}$ and then by deep convection $(\mathrm{Cb})$. The relatively low reflectivities (i.e., less than $0 \mathrm{dBZ}$ ) encountered in the cirrus shield covering the eye increase sharply to more than $15 \mathrm{dBZ}$ at altitudes in excess of $15 \mathrm{~km}$ for a span of more than $20 \mathrm{~km}$ in correspondence to the right eyewall (distance $190 \mathrm{~km}$ ), indicating strong convective activity, a possible precursor to the intensification to supertyphoon status less than 2 days later [10].

\section{COMPOSITE CLOUD CHARACTERISTICS}

In this section we combine all seventeen cases to create a composite set of characteristics relative to the storm center. We use the contoured frequency by altitude diagram (CFAD), developed by Yuter and Houze [11], to present a histogram of ice properties at each altitude. This approach provides a concise summary of vertical structure and could also be used in future work for comparison of model output with observations. Fig. (11) shows CFADs for the observed reflectivity in the eyewall region and in the surrounding stratiform regions. The eyewall region is defined as being 90 $\mathrm{km}$ or less from storm center and having PCT $<255 \mathrm{~K}$. The CFADs shows that eyewall reflectivity is slightly larger and more vertically developed. However, the maximum reflectivity difference is much less than might be observed at lower frequencies due to the reflectivity limit imposed by nonRayleigh scattering at W-band. The strength of the eyewall convection is better seen by noting the much-reduced reflectivity near the surface due to the large attenuation in the eyewall. The mean AMSR-E surface rain rate in the eyewall region is $9.2 \mathrm{~mm} / \mathrm{h}$, in contrast with $2.3 \mathrm{~mm} / \mathrm{h}$ for the stratiform region. The maximum eyewall rain rate over all cases is $28.4 \mathrm{~mm} / \mathrm{h}$ in Typhoon Ewiniar. 

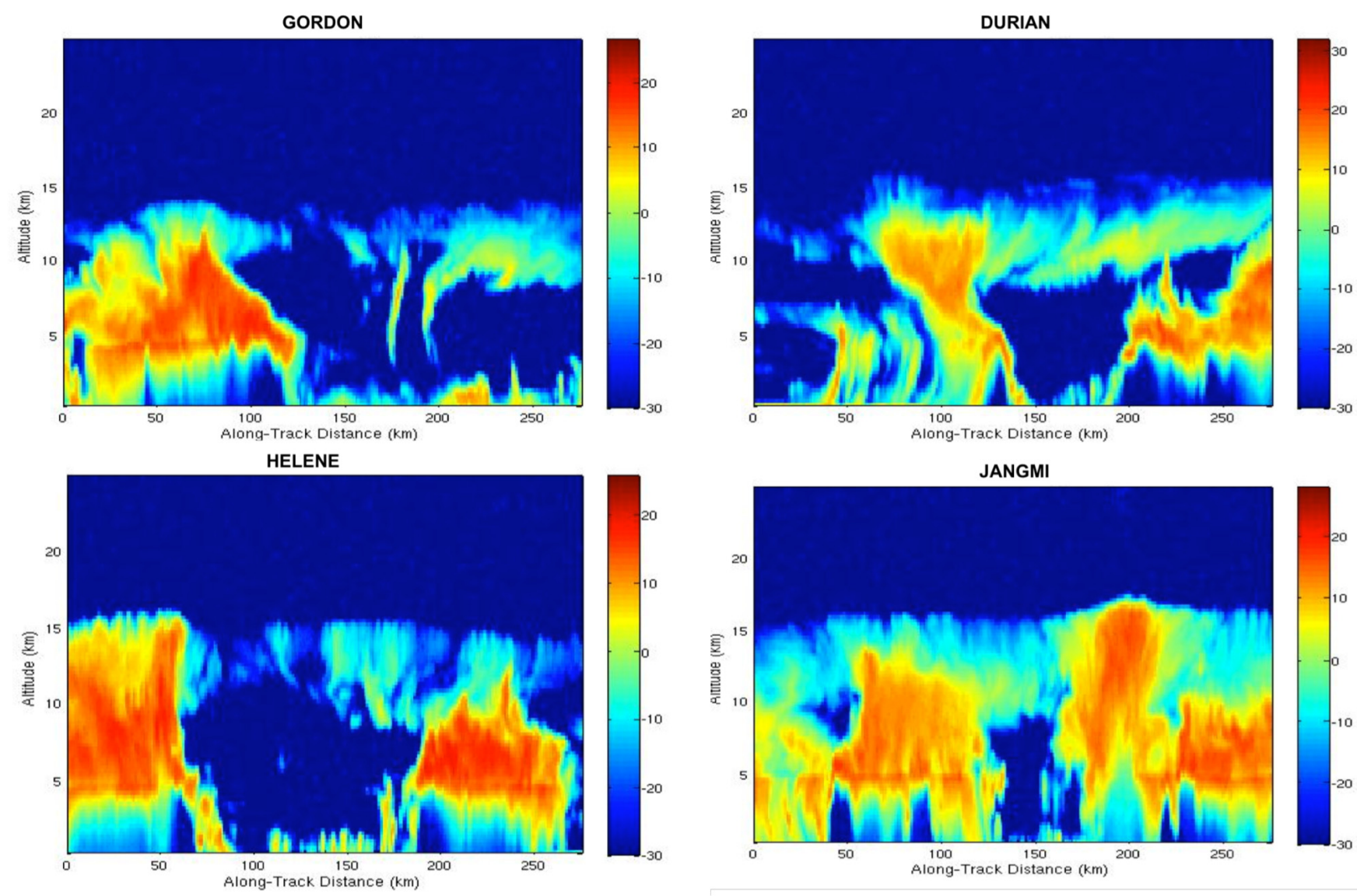

Fig. (9). CPR reflectivity for eye and surrounding regions of Gordon (upper left), Helene (lower left), Durian (upper right), and Jangmi (lower right). Freezing level is typically near or slightly above $4.5 \mathrm{~km}$ altitude.

Fig. (12) shows CFADs for various ice parameters retrieved in eyewall regions of the 16 cases, and Fig. (13) shows CFADs for the same parameters retrieved in stratiform regions. The PSD width CFADs for eyewall and stratiform in Figs $(12,13)$ are very similar, with width decreasing with increasing altitude, consistent with assumptions in the single-frequency radar retrieval algorithm [9]. Generally, particle radius decreases with altitude while number concentration increases. The effective particle radius is typically larger for eyewall than stratiform areas, especially near 10 $\mathrm{km}$ altitude. The eyewall region peak ice water content is about $1.5 \mathrm{~g} / \mathrm{m}^{3}$ at an altitude of $10 \mathrm{~km}$, while stratiform areas peak at around $0.5 \mathrm{~g} / \mathrm{m}^{3}$ at an altitude of $9 \mathrm{~km}$. At these altitudes the peak number concentration is nearly 400 per $\mathrm{L}$ in the eyewall and above 200 per L in stratiform areas. The ranges of parameters observed by CPR are reasonably consistent with in situ observations, although the CloudSat retrievals could be affected by attenuation from large ice particles, especially within the eyewall. The observations just above the melting level (6 km altitude) reported in [12] show ice water contents of $1-4 \mathrm{~g} / \mathrm{m}^{3}$ and ice particle concentrations of $40-350$ per L. Based on measurements of water content in hurricane eyewalls [13], Merritt and Wexler [7] estimate ice contents of up to $4 \mathrm{~g} / \mathrm{m}^{3}$ in cirrus canopies near the eyewall, dropping to $1 \mathrm{~g} / \mathrm{m}^{3}$ toward the outer edge. Heymsfield et al. [14] report particle concentrations up to 400 per $\mathrm{L}$ and water contents up to $1.7 \mathrm{~g} / \mathrm{m}^{3}$, with large variability.
Fig. (14) shows CFADs for the CPR cloud classification. Because the deep convection class generally applies to the entire CPR beam (where cloud is present), it contains essentially no altitude information. Hence, the deep convection class was excluded from the CFADs so as to not obscure the cloud classes that do vary with altitude. The two CFADs are similar, although the stratiform areas have relatively more altocumulus and nimbostratus. The clouds classified as altocumulus also tend to be at a higher altitude in the stratiform areas.

\section{DISCUSSION}

The hurricane cloud structure documented here through CloudSat and A-Train observations is in general agreement with early aircraft observations [15-18] of an eye surrounded by a cumulonimbus wall and possibly containing a stratocumulus hub cloud [19]; a thick cirrus canopy emanating from the eyewall and transitioning below to an altostratus layer; and a surrounding area with a mix of cloud types (e.g., cumulonimbus, cumulus, stratus, stratocumulus) underneath the cirrus canopy. Ileana, Prapiroon, Durian, Gordon, Helene, and Jangmi all show low-level clouds in the eye; these are classified as cumulus, stratocumulus, or nimbostratus. Similar clouds are seen in the gaps between rainbands in the CPR data, along with mid-level altocumulus. A clear region between the hub cloud and eyewall has been reported on occasion and has been associated with the eye size relative to the Rossby length [20]. Evidence of a clear region 

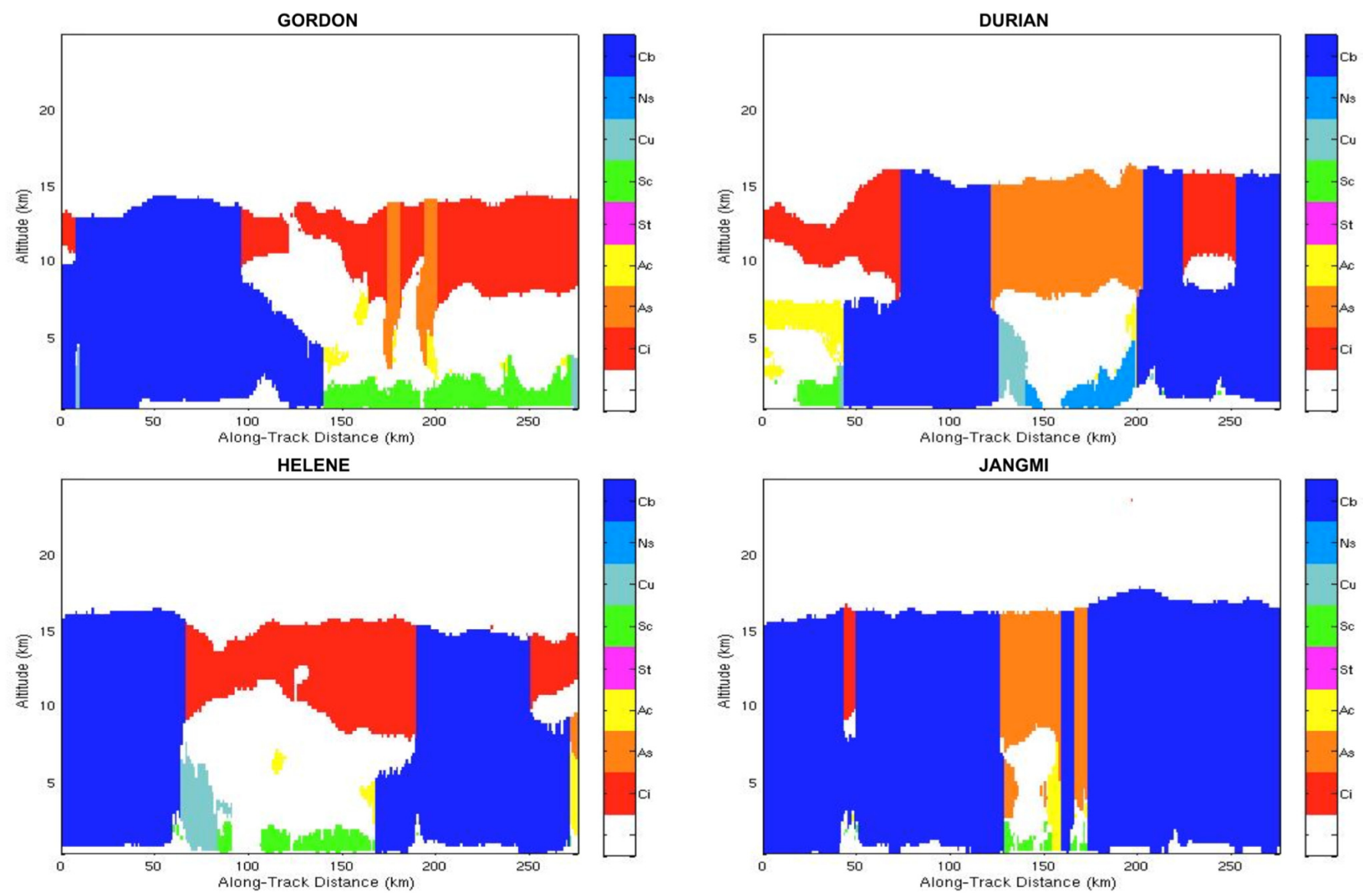

Fig. (10). CloudSat cloud classification for eye and surrounding regions of Gordon, Helene, Durian, and Jangmi. Freezing level is typically near or slightly above $4.5 \mathrm{~km}$ altitude.
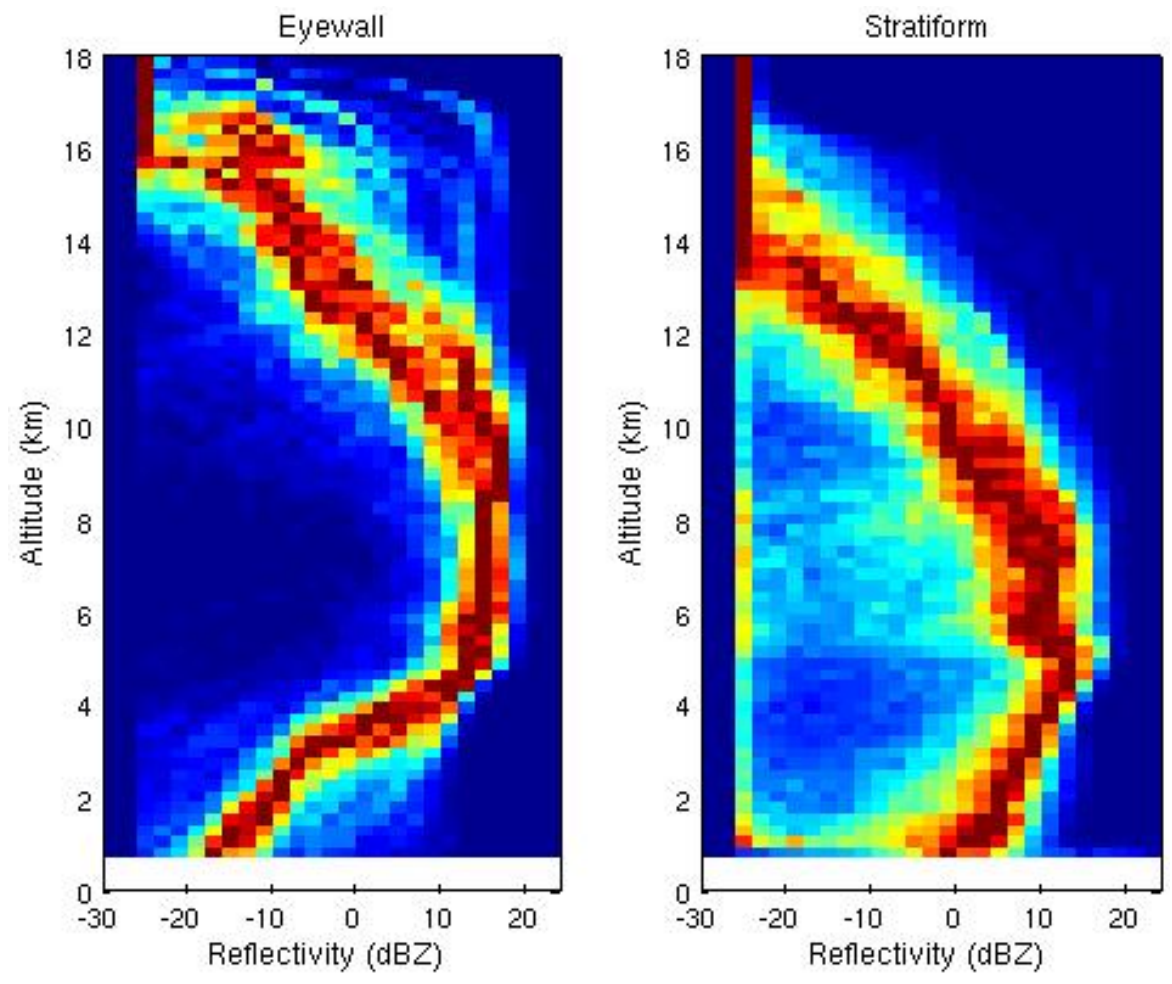

Fig. (11). Contoured frequency by altitude diagrams (CFADs) for CPR measured reflectivity in tropical cyclone eyewall regions (left) and stratiform regions (right). The relative occurrence ranges from lowest (blue) to moderate (yellow) to highest (red). 

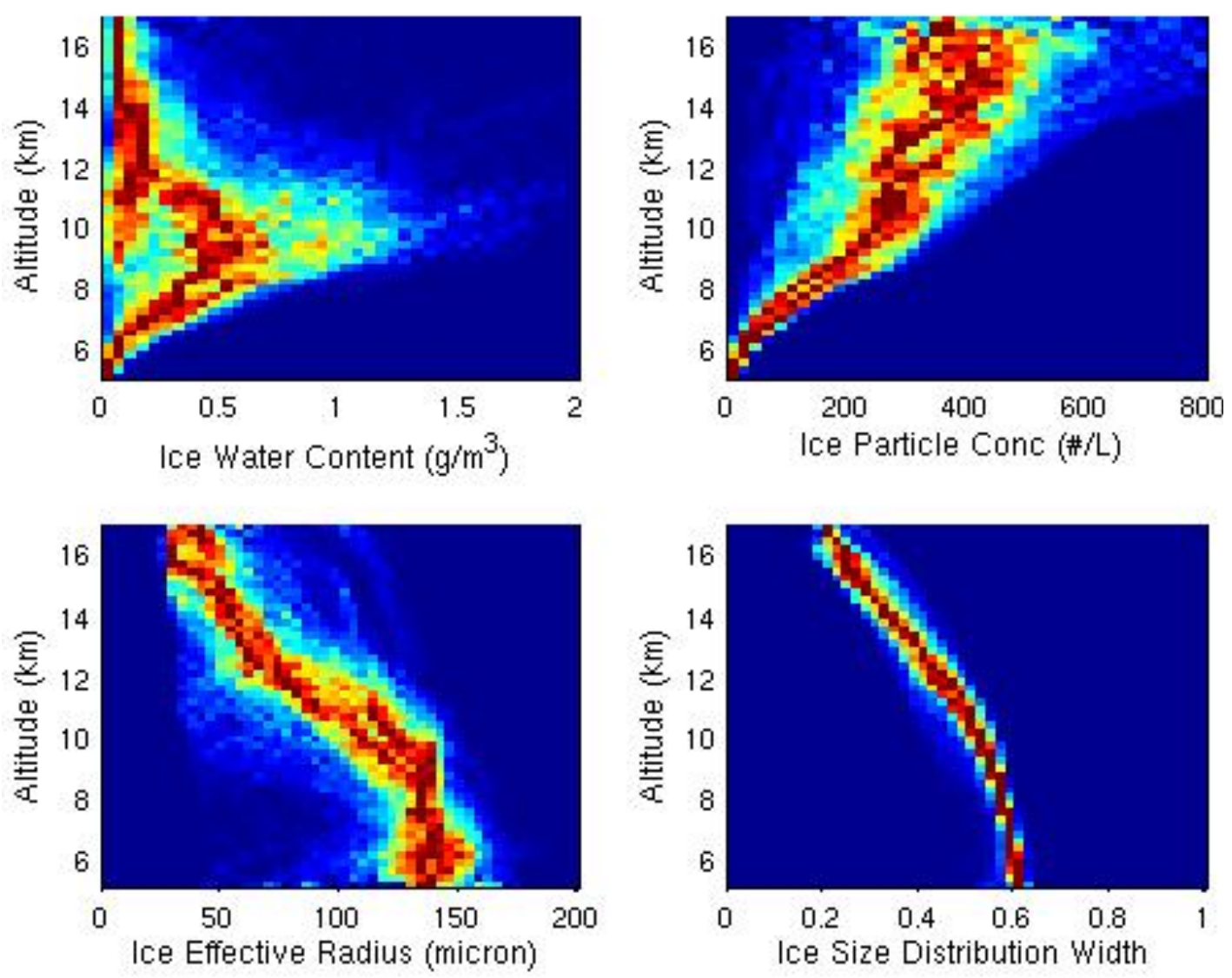

Fig. (12). Ice parameter CFADs in tropical cyclone eyewall regions.
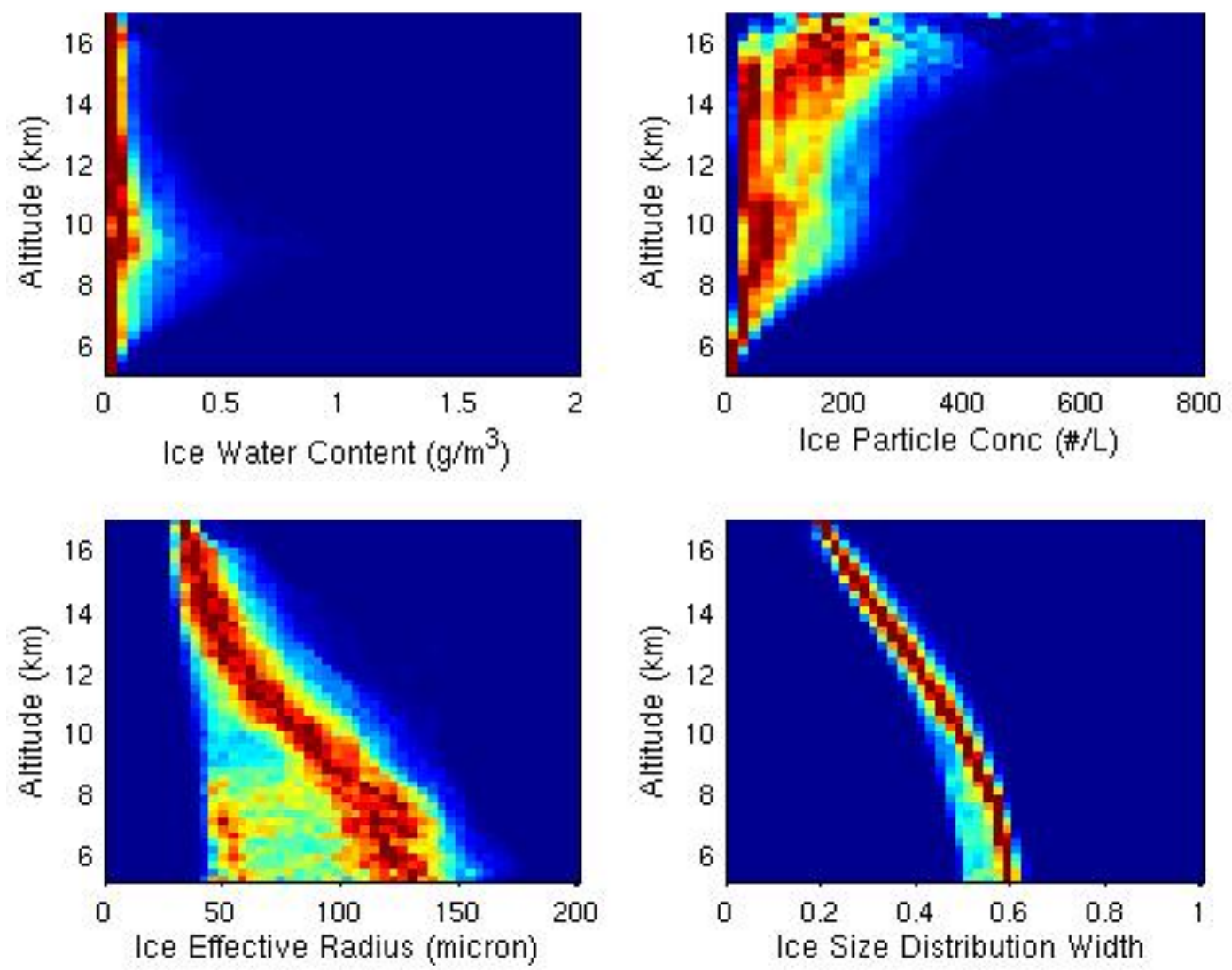

Fig. (13). Ice parameter CFADs in tropical cyclone stratiform regions. 

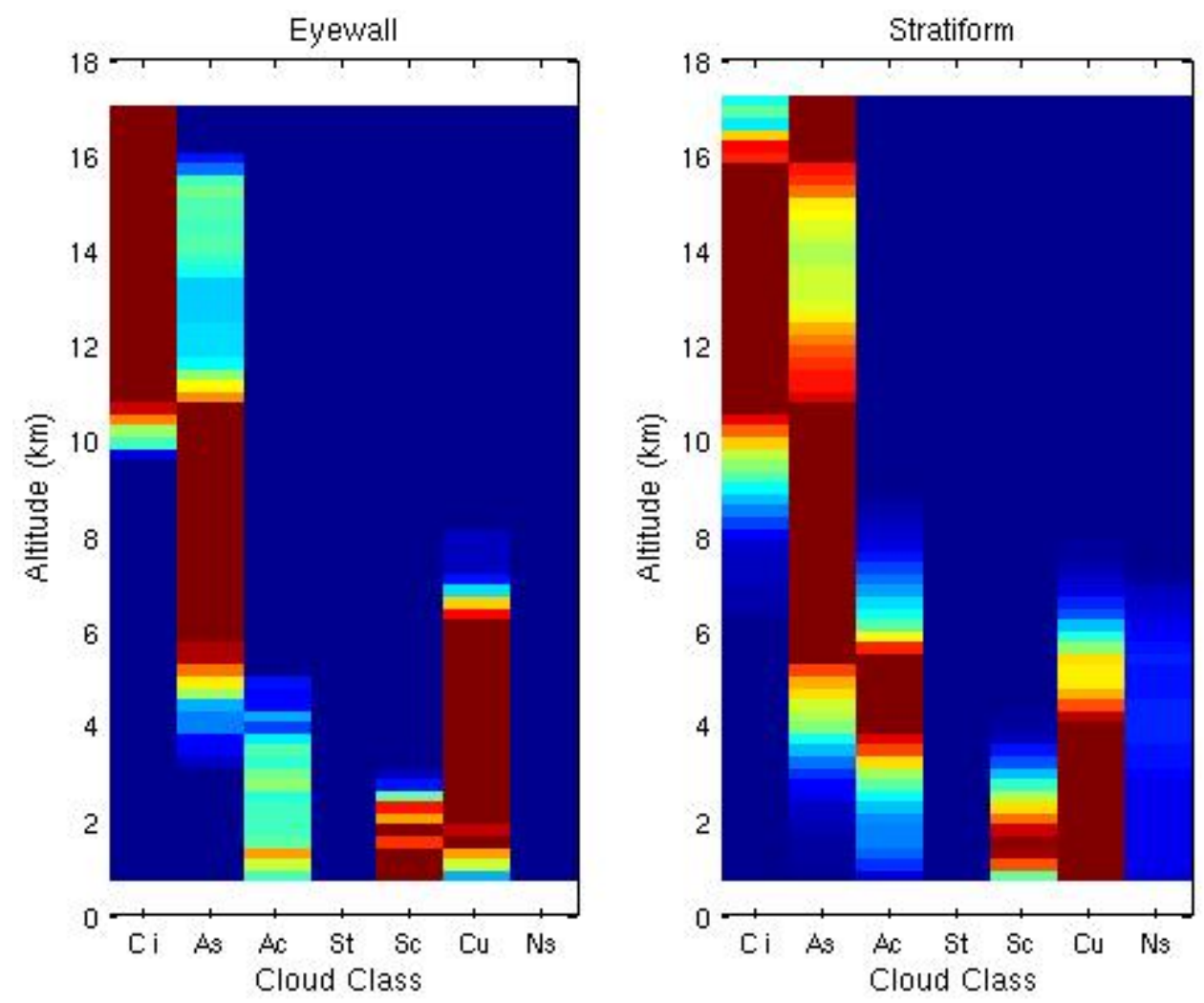

Fig. (14). CFADs of cloud classification in the eyewall (left) and stratiform regions (right).

between the eyewall and a hub cloud at the eye center may be visible in CPR observations of Prapiroon (Fig. 6 at 400 $\mathrm{km}$ ) but is not obvious in the other five cases. In [21] evaporating precipitation within the eye is noted as a possible but unlikely mechanism by which the eye can be moistened. The hub cloud in Prapiroon has rather large reflectivity and may be precipitating, as may be the case in Durian; no evidence of precipitation was noted in the other cases, although drizzle just above the surface could be missed because of surface clutter. One CPR-observed eye feature common to all cases is a cirrus layer over the eye.

More recent in situ observations by aircraft have provided information on the ice microphysics associated with the cloud structures. The analyses of Black and Hallett [22, 23] and Houze et al. [12] indicate that small graupel is formed and lifted in the eyewall along outward sloping trajectories; ice crystals formed through secondary nucleation [24] near the eyewall and in the outflow layer sink and aggregate, eventually forming stratiform precipitation. Homogenous droplet freezing near the eyewall may also generate small ice particles [14]. These processes are consistent with a reduction in ice water content and particle size with altitude, as seen in our data. In eyewall updrafts the larger particles have a larger terminal velocity and cannot be carried to the higher altitudes. Away from the eyewall, sinking ice particles first grow by vapor deposition and then by aggregation as they reach lower, warmer altitudes. Aggregation results in larger but fewer particles, reducing the number concentration with decreasing altitude, as seen in the CPR data. This conceptual model is also discussed by Cecil and Zipser [25] and is in accord with their combined radiometer, 14-GHz radar, and lightning observations of tropical cy- clones using Tropical Rainfall Measuring Mission data. The outward slope of the eyewall is consistent with the CPR observations here and with lidar observations in [19]. In spite of the general consistency of the CPR data with this microphysical concept, the data also show that there is large variability both between and within storms.

\section{ACKNOWLEDGMENTS}

The authors would like to thank Ms. Natalie Tourville of CSU for making her overpass database publicly available and the anonymous reviewers for their helpful comments. The research described in this paper was carried out at the Jet Propulsion Laboratory under contract with the National Aeronautics and Space Administration. Support from the CloudSat/CALIPSO Science Program, the CloudSat Project, the Precipitation Measurement Missions Program, and the Aqua/AMSR-E Validation Program is gratefully acknowledged.

\section{REFERENCES}

[1] Stephens GL, Vane DG, Tanelli S, et al. CloudSat mission: performance and early science after the first year of operation. J Geophys Res 2008; 113: D00A18, doi:10.1029/2008JD009982.

[2] Evans WFJ. Hurricane structure. Presentation at CloudSat Science Team Meeting. Hawaii 2006.

[3] Marks FD. State of the science: radar view of tropical cyclones. Meteorological Monogr 2003; 30(52): 33-74.

[4] Luo Z, Stephens GL, Emanuel KA, Vane DG, Tourville ND, Haynes JM. On the use of CloudSat and MODIS data for estimating hurricane intensity. IEEE Geosci Remote Sens Lett 2008; 5(1): 13-6.

[5] Houze RA, Chen SS, Smull BF, Lee W-C, Bell MM. Hurricane intensity and eyewall replacement. Science 2007; 315:1235-9. 
[6] Sassen K, Wang Z. Classifying clouds around the globe with the CloudSat radar: 1-year of results. Geophys Res Lett 2008; 35: L04805, doi:10.1029/2007GL032591.

[7] Merritt ES, Wexler R, Cirrus canopies in tropical storms. Mon Wea Rev 1967; 95(3): 111-20.

[8] Spencer RW, Goodman HM, Hood RE. Precipitation retrieval over the land and ocean with the SSM/I: identification and characteristics of the scattering signal. J Atmos Oceanic Technol 1989; 6: 254-73.

[9] Austin RT, Heymsfield AJ, Stephens GL. Retrieval of ice cloud microphysical parameters using the CloudSat millimeter-wave radar and temperature. J Geophys Res 2009; 114: D00A23, doi:10.10 29/2008J D010049.

[10] Kelley OA, Stout J, Halverson JB. Tall precipitation cells in tropical cyclone eyewalls are associated with tropical cyclone intensification. Geophys Res Lett 2004; 31: L24112, doi:10.1029/2004GL 021616.

[11] Yuter SE, Houze RA. Three-dimensional kinematic and microphysical evolution of Florida cumulonimbus. Part II: frequency distributions of vertical velocity, reflectivity, and differential reflectivity. Mon Wea Rev 1995; 123(7): 1941-63.

[12] Houze RA, Marks FD, Black RA. Dual-aircraft investigation of the core of Hurricane Norbert. Part II: mesoscale distribution of ice particles. J Atmos Sci 1992; 49(11): 943-62.

[13] Ackerman B. Some observations of water contents in hurricanes. J Atmos Sci 1963; 20(4): 288-98.

[14] Heymsfield AJ, Bansemer A, Durden SL, Herman RL, Bui TP. Ice microphysics observations in Hurricane Humberto: comparison with non-hurricane-generated ice cloud layers. J Atmos Sci 2006; 63(1): 288-308.

[15] Simpson RH. Exploring eye of typhoon marge, 1951. Bull Am Meteor Soc 1952; 33(7): 286-98.

[16] Kessler E. Eye region of Hurricane Edna, 1954. J Meteorol 1958; 15: 264-70.

[17] Malkus JS, Ronne C, Chaffee M. Cloud patterns in Hurricane Daisy, 1958. Tellus 1961; 13: 8-30.

[18] LaSeur NE, Hawkins HF. An analysis of Hurricane Cleo (1958) based on data from research reconnaissance aircraft. Mon Wea Rev 1963; 91: 694-709.

[19] Kovacs TA, McCormick MP. Observations of Typhoon Melissa during the Lidar In-space Technology Experiment (LITE). J Appl Meteorol 2003; 42(7): 1003-13.

[20] Schubert WH, Rozoff CM, Vigh HL, McNoldy BD, Kossin JP. On the distribution of subsidence in the hurricane eye. Q J R Meteorol Soc 2007; 133: 1-20.

[21] Willoughby HE. Tropical cyclone eye thermodynamics. Mon Wea Rev 1998; 126: 3053-67.

[22] Black RA, Hallett J, Observations of the distribution of ice in hurricanes. J Atmos Sci 1986; 43(8): 802-22.

[23] Black RA, Hallett J. Electrification of the hurricane. J Atmos Sci 1999; 56(12): 2004-28.

[24] Cantrell W, Heymsfield A. Production of ice in tropospheric clouds. Bull Am Meteor Soc 2005; 86(6): 795-807.

[25] Cecil DJ, Zipser EJ. Reflectivity, ice scattering, and lightning characteristics of hurricane eyewalls and rainbands. Part II: intercomparison of observations. Mon Wea Rev 2002; 130(4): 785-801.

(C) California Institute of Technology, USA; Licensee Bentham Open.

This is an open access article licensed under the terms of the Creative Commons Attribution Non-Commercial License (http://creativecommons.org/licenses/by$\mathrm{nc} / 3.0 /$ ) which permits unrestricted, non-commercial use, distribution and reproduction in any medium, provided the work is properly cited. 